\title{
EDITORIAL
}

\section{Childhood maltreatment and health outcomes}

\author{
Rodrigo Grassi-Oliveira iD \\ Graduate Program of Medicine and Medical Sciences: Neuroscience, Instituto do Cérebro (InsCer), Escola de Medicina, Pontifícia \\ Universidade Católica do Rio Grande do Sul (PUCRS), Porto Alegre, RS, Brazil. iD https://orcid.org/0000-0001-9911-5921
}

Childhood maltreatment has been recognized as a widespread problem across the globe. ${ }^{1}$ Data from North America have shown higher annual health care utilization and costs for women with vs. without a history of child abuse. ${ }^{2}$ Specifically, annual health care costs were $36 \%$ higher for women who had experienced both physical and sexual child abuse. Feng et al. found that the economic burden of child maltreatment in the United States was U\$ 585 billion in just 1 year, ${ }^{3}$ and U\$ 194 billion in the East Asia and Pacific region, accounting for 1.36 to $2.52 \%$ of the region's GDP. ${ }^{4}$

In addition to representing an economic burden, childhood abuse and neglect are important risk factors for a range of mental disorders, including addiction and suicide, as well as for sexually transmitted infections and risky sexual behavior. ${ }^{5}$

Regarding biological mechanisms linked to the effects of early adversity on poor health outcomes, there is consistent evidence indicating that accelerated biological aging may play an important role ${ }^{6}$ including in groups with substance use disorders. ${ }^{7}$

The present issue of the Brazilian Journal of Psychiatry brings three important articles in the area of childhood maltreatment in the context of low and middle-income countries. Shamohammadi et al. $^{8}$ explored the prevalence of maltreatment and found a relatively low frequency (7.1\%) of trauma symptoms among 11-12 year old children from Iran. In Brazil, Diehl et al..$^{9}$ examined adult patients seeking treatment for drug abuse and found a high prevalence of reported physical and sexual abuse, as well as an association between childhood maltreatment and later risky sexual behavior in adulthood. Novel data from Colombia, presented by Jimenez et al., ${ }^{10}$ are used to explore for the first time the association among telomere length, childhood trauma, and depressive symptoms in a Latin American sample, suggesting a moderate correlation between telomere length and scores of sexual abuse in the Childhood Trauma Questionnaire. Such a diverse perspective provides readers with a valuable opportunity to broaden and deepen their knowledge of the field of childhood maltreatment.

\section{Disclosure}

The author reports no conflicts of interest.

\section{References}

1 Viola TW, Salum GA, Kluwe-Schiavon B, Sanvicente-Vieira B, Levandowski ML, Grassi-Oliveira R. The influence of geographical and economic factors in estimates of childhood abuse and neglect using the Childhood Trauma Questionnaire: A worldwide metaregression analysis. Child Abuse Negl. 2016;51:1-11.

2 Bonomi AE, Anderson ML, Rivara FP, Cannon EA, Fishman PA, Carrell D, et al. Health care utilization and costs associated with childhood abuse. J Gen Intern Med. 2008;23:294-9.

3 Fang X, Brown DS, Florence CS, Mercy JA. The economic burden of child maltreatment in the United States and implications for prevention. Child Abuse Negl. 2012;36:156-65.

4 Fang X, Fry DA, Brown DS, Mercy JA, Dunne MP, Butchart AR, et al. The burden of child maltreatment in the East Asia and Pacific region. Child Abuse Negl. 2015;42:146-62.

5 Norman RE, Byambaa M, De R, Butchart A, Scott J, Vos T. The longterm health consequences of child physical abuse, emotional abuse, and neglect: a systematic review and meta-analysis. PLoS Med. 2012;9:e1001349-e1001349.

6 Ridout KK, Levandowski M, Ridout SJ, Gantz L, Goonan K, Palermo $\mathrm{D}$, et al. Early life adversity and telomere length: a meta-analysis. Mol Psychiatry. 2018;23:858-71.

7 Levandowski ML, Tractenberg SG, de Azeredo LA, De Nardi T, Rovaris DL, Bau $\mathrm{CH}$, et al. Crack cocaine addiction, early life stress and accelerated cellular aging among women. Prog Neuropsychopharmacol Biol Psychiatry. 2016;71:83-9.

8 Shamohammadi M, Salmanian M, Mohammadi MR, Sadeghi Bahmani D, Holsboer-Trachsler E, Brand S. Prevalence of self-reported trauma in a sample of Iranian children is low and unrelated to parents' education or current employment status. Braz J Psychiatry. 2019;41:208-12.

9 Diehl A, Clemente J, Pillon SC, Santana PRH, da Silva CJ, Mari JJ. Early childhood maltreatment experience and later sexual behavior in Brazilian adults undergoing treatment for substance dependence. Braz J Psychiatry. 2019;41:199-207.

10 Jiménez KM, Pereira-Morales AJ, Adan A, Forero DA. Telomere length and childhood trauma in Colombians with depressive symptoms. Braz J Psychiatry. 2019;41:194-8. 